\title{
Sôbre a Evolução do Problema do Direito Natural*.
}

\author{
Nelson Nogueira Saldanha \\ (Docente-livre de Direito Constitucional na \\ Fac. de Direito da Univ. Federal de \\ Pernambuco).
}

\begin{abstract}
SUMÁrIo: Liberdade e direito natural nos tempos modernos: ligação entre suas trajetórias. Peripécias do jusnaturalismo contemporâneo: seus desdobramentos e suas dificuldades. "Direito" natural e "teoria" do direito natural: anotação à margem dos livros sôbre direito natural. Reflexões pouco conclusivas.
\end{abstract}

Qual o interêsse, para povos na situação do brasileiro, de questões como a de direito natural? À primeira vista, poderia parecer que semelhante classe de temas, cujo contôrno se acha marcado com as características de uma origem estranha à nossa experiência cultural, não interessa à ordem de premências que hoje estão necessitadas de discussão entre nós; poderia parecer que os problemas que conduziram o desenvolvimento da teoria do direito natural, sendo problemas situados na história dos povos europeus, não encontram correspondência concreta no caso da dos povos ditos periféricos. Em realidade, é preciso convir que todo problema doutrinário tem um condicionamento hisiórico, e os conjuntos de conceitos e de categorias, que formam um tema como o do direito natural, surgiram e cresceram sob aquêle condicionamento. Mas nem isso impede, antes certamente permite, que a questão das metamorfoses do direito

* Conferência pronunciada em 17 de setembro de 1955 na Faculdade de Direito de Caruarú, Pernambuco. 
natural seja revista dentro dos niveis intelectuais da vida brasileira, tal como nos propomos aquí sugerir ou tentar: não só porque os países como o nosso precisam sempre das lições da história dos outros, desde que lùcidanente entendidas, como porque, onde quer que se estude o Direito, semelhante questão se reveste de vibrante importância.

\section{Liberdade e Direito natural nos tempos modernos.}

De certo modo, as experiências passadas da humanidade vêm tendo o seu perfil traçado, ou retraçado, em função de experiências novas. Assim, o que se chamou de "liberdade antiga" foi algo cuja descrição serviu no século XIX para contraste perante a idéia liberal de liberdade; e outros elementos da vida de outras épocas, como o direito ou a pedagogia, têm seus caracteres reconstruídos tôda vez que uma geração quer, servindo-se da história, dar fundo propício ao que faz ou quer fazer.

No caso da idéia de liberdade, que em si mesma corresponde a uma vivência intransferivel, a sua conceituação durante o liberalismo utilizou, como tela ou marco arqueológico, o quadro da polis em que o indivíduo - dizia-se era absorvido, mesmo na medida em que fôsse livre, pela comunidade política e cultural. Note-se que a ciência histórica, que trabalhava sôbre os temas clássicos, se abeberava dos princípios daquele mesmo liberalismo moderno, a que alimentava.

Olhando-se, agora, os componentes da gênese e da evolução dessa teoria moderna da liberdade, encontramos, ao lado do condicionante social, ou seja do predomínio crescente da classe burguesa e de seus padrões econômicos, uma série de ingredientes culturais: a secularização da mentalidade, o individualismo, o racionalismo. Assim, a teoria da liberdade, desenvolvida nos marcos burgueses, vinha sincronizada com um racionalismo que tudo queria pôr em princípios corretos, em evidências geométricas, em fórmulas 
universais; entretanto ela, aquela teoria, tomou gôsto em montar comparações históricas, e em distinguir-se por elas de tudo o que era antigo: democracia antiga, direito antigo. Por um lado suas matrizes clássicas a ligavam ao direito natural, a um direito imutável, desdobrável em direitos inerentes a cada qual, atomizados e pré-positivos; por outro, sua consciência de modernidade, que descrevia seu regime social como coisa nova, moldava-lhe uma vocação histórica.

Êsse tema é de suma importância. A teoria moderna da liberdade nasceu em paralelo com a da democracia burguesa, e ambas cresceram como oposição a regimes sociais e políticos, cuja queda fêz que tais teorias se generalizassem. Mas nêsse processo elas vinham levantando complicadas problemáticas, de sorte que desde o advento da democracia liberal os movimentos políticos são ocasião, sempre, de discussão, e nenhum regime pôde mais dispensar a autojustificação. A teoria liberal tinha de se justificar em cada passo, pondo aliás com isso questões permanentes. Sucedeu entâo que, de dentro mesmo dos temas que surgiram, cresceu a oposição entre a matriz clássica universalizante e intemporalizante da teoria liberal e sua tendência a fazer história e a justificar mutações. A matriz clássica era o cartesianismo trazido para a política, a tendência a tirar da razão, e só dela (ou do bom senso como às vêzes se dizia) as bases das instituições; tendência frutificada inclusive em Rousseau, na medida em que seu ideal político supunha uma específica "razâo política" de base individual e apesar da derrapagem comunitarista que sua "vontade geral" envolvia. Era universalizante e intemporalizante, e nêsse sentido, bem do século xvin, o direito natural era um perfeito complemento, senão um fundamento, da idéia de liberdade. Chegou-se ao ponto em que, numa certa fase, falar de direito natural e de filosofia do direito era a mesma coisa. Já a necessidade de alusões históricas, que havia na temática das discussões como que se autojustificava o ideal demoliberal, trazia consigo a idéia de que certas mudanças 
históricas são necessárias, senão mesmo a idéia da história como ordem de mudanças necessárias. Por um tempo, falou-se apenas de PÉrICles, da democracia grega e de coisas assim, que os inglêses do tempo de Grote muito apreciavam; depois, porém, a filosofia assumiu o tema, e viu-se Hegel, entusiasta da revolução francesa, estabelecer a idéia da racionalidade essencial de tôda transformação real. E os juristas da Escola Histórica - apesar da pouca simpatia de Savigny por Hegel -- deram à noção de direito um tratamento, em que o jusnaturalismo clássico ficava mal colocado: agora o fundamental era o conjunto orgânico da vida do povo, como berço do direito, um conjunto tomado em concreto, como uma coisa real.

Para o problema da situação histórica do conceito de liberdade moderna, v. meu Liberdade moderna e história da liberdade em Anais do IV Congresso Brasileiro de Filosofia - S. Paulo - Fortaleza, 1962. O problema, no caso da liberdade, será o de situar as circunstâncias institucionais, necessárias para "fazer" história, sem desligar do "sentimento" de liberdade, sinal de sua efetiva existência. Sôbre - desencadeamento de teorizações justificadoras de regimes e de contra-regimes desde as revoluções liberais, meu Notas para una tipologia de las mentalidades políticas, em Estudios de Sociología, n. 2, Buenos Aires, 1962. - No artigo "Liberty", na Encyclopaedia of Social Sciences (ed. de 1935. vol. IX), H. LASKI encontra dois grandes períodos na evolução da liberdade desde a Reforma: primeiro, o da luta pela libertação do indivíduo perante travas religiosas, econômicas, políticas, com sentido negativo, por ser mais uma luta pela liberdade "contra" algo; segundo, o das lutas sociais, pedindo-se uma liberdade para todos, com sentido positivo por ser já uma luta por uma liberdade "para" algo. O mesmo esquema é adotado por Fromm em seu Mêdo da Liberdade, mas, apesar de sugestivo, é muito simplificador e discutível: porque na fase do individualismo a pugna contra pressões de origem medieval era também impulso "a favor" de certos fins, valores ou concessões, e na fase social a referência a positividades visadas não dispensa o complemento, que é a necessidade de livrar-se "de" situações que obstem as pretensões. 


\section{Peripécias do jusnaturalismo contemporâneo.}

A posição da Escola Histórica, porém, não foi a palavra definitiva sôbre o Direito Natural, e há hoje uma série de revisões do tema, a ter em conta. Felizmente, aliás.

Há que considerar, na trajetória do direito natural durante o largo processo que os historiadores chamam de "advento dos tempos modernos", a sua divisão em uma corrente teológica e outra secularizada. Ou antes: o direito natural de linha teológica, que vinha dos claustros da Idade Média, continua a atuar literàriamente depois da Reforma luterana (e continua sobretudo entre os jesuitas espanhóis), mas agora coexistindo com uma nova e poderosa versão do direito natural, conduzida em sentido secular e racionalista, vinculada à cultura dos países protestantes.

O que sucedia era algo paralelo ao caso da teoria do contrato social; esta teoria, cultivada durante a Idade Média e bastante conhecida pelos escritores dos séculos xIII a xvi, assume depois, com Hobbes, Locke e Rousseau, uma importância tão realçada, que é como se se tratasse de uma formação doutrinária inteiramente nova. Cada uma das grandes teorias contratualistas carregou, por sinal, uma determinada concepção do direito natural e dos direitos naturais: uma em HoBBes, outra em Locke etc..

Voltando, porém, ao ramo secularizado-racionalista do jusnaturalismo, êle informou uma bôa parte do pensamento social nos séculos xvir e xviII, servindo orientações diferentes, mas sempre marcando a temática jurídico-política por um padrão expositivo tipicamente apriorista e dedutivista. O jusnaturalismo moderno se generalizou, assim, como um "momento" do próprio espírito europeu em seu desenvolvimento, como um elemento dentro do grande fenômeno da "secularização" da mentalidade ocidental.

Havia, entretanto, problemas e percalços, no tocante à relação entre o jusnaturalismo e a teoria da liberdade, que viria a ser alcançada por uma série de reivindicações sociais. 
Um detalhe a que pouca gente prestou a atenção, foi o fato de que, segundo o jusnaturalismo clássico, a concepção ideal da sociedade se plasmava como um todo unitário e - um tanto leibnizeanamente - harmonioso. A ordem política deveria assentar-se sôbre a substância de um grupo social perfeitamente coeso. Isso conduzia, por conseqüência, a uma resistência à idéia de partidos: e por isso êles foram chamados, por muito tempo, de "facções" e "seitas". $\mathrm{E}$ ocorreu que, inclusive pelas necessidades e conveniências do parlamentarismo inglês, tornado modêlo, a democracia liberal consagrou os partidos e chegou a dar-lhes o caráter de essenciais à liberdade política: havia nisso uma implícita concessão à parte de "movimento" que devia haver na vida política, por cima do ideal um tanto estático que aquela harmonia representava.

De qualquer sorte, o direito natural se integrou na experiência democrática. O século xviII, cuja ideologia segundo Carl Becker era uma espécie de terrestrização da "cidade de Deus" agostiniana, construíu as suas reclamações sôbre a idéia de uma ordem naturalmente desejável, na qual a vontade individual livre (na verdade a vontade burguesa) era o "organon" e o "metron" para todas as dimensões. A liberdade era um dos direitos, ditos inatos e inalienáveis, mas era, antes disso e mais do que isso, a condição de tôda ordem. Assim as definições de "direito" - modêlo, a de KANT - tomaram a liberdade como marco, e a pluralização dela como sistema.

Talvez as consciências daquele tempo não tenham visto tudo assim; mas a história é um rever, em que os protagonistas não sabem de seus espectadores futuros.

O certo é que, para a compreensão que hoje se projeta sôbre tudo aquilo, a Revolução Francesa foi um episódio jusnaturalista: quer dizer, um movimento em cujo arsenal de idéias os princípios do Direito Natural ocupavam parte eminente, e êsse arsenal de idéias era, ocioso è dizer, o de todo o século xvir. Há, porém, mais ainda: dada a exemplaridade histórica que aquela revolução assumiu, chegou 
a formar-se a opinião de que em "tôda" revolução atua uma idéia jusnaturalista, pois que todo embate consciente contra uma ordem dada implica a fé em valores superiores, implica a opinião de que, "acima" da positividade da ordem a derrubar, vigoram preceitos cujo valor independe da vigência concreta mas que é legítimo fazer vigorar por meio da luta. Já existe sôbre isso, por sinal, um vasto rosário de referências, mais explicitas umas, outras menos. O que sucede é que êste paralelo, entre revolução em geral e jusnaturalismo em geral, reduz ambas as coisas e representações um tanto esquemáticas e bastante amplas, ficando por isso ao alcance da crítica histórica, sempre faminta de peculiaridades e de "diferenças específicas"

Retomemos, porém, a situação da teoria social da democracia. Ela, tendo nascido em berço geométrico, instalada nos claros meridianos individualizantes e universalizantes do classicismo, adotou em tempo as inovações trazidas pelas escolas de ciência social, e eram as contribuições da filologia, da etnografia, da sociologia, de permeio com as escolas "históricas" de política, de direito e de economia. Essas inovações em têrmos de ciência social puxavam o ideário democrático para terreno concreto, em que impressionava antes de tudo o espetáculo do variável: as coisas humanas, nos grupos ou nas pessoas, passavam a ser vistas como variabilidade no tempo e no espaço, conforme séculos e épocas, ou continentes e climas. Isso era propício ao desenvolvimento de uma tendência da doutrina democrática, mencionada atrás, a de pôr o debate em têrmos de história.

Mas então o direito natural, categoria típica da forma de pensar universalizante, ficava difícil de conciliar com essas novas tendências. A sociologia, desde Corte, repudiava a idéia abstrata dos direitos, taxados de metafísicos; as escolas históricas enxergavam por tôda parte sistemas concretos, com contòrnos e condicionamentos bem situados; a filosofia crítica impugnava todo apriorismo. Foram, portanto, très os "fronts" em que se viu combatida a venerável e já então encanecida figura do direito natural: a) o po- 
sitivismo sociológico, vinculado ao empirismo em geral e aos sociologismos e evolucionismo de tôda sorte, incluindo os etnografistas do direito; b) o criticismo gnoseológico e epistemológico, rejeitador de sistemas de cunho dogmático, que atingia justamente as matrizes pufendorfianas e wolfianas do direito natural de até começos do século XIX; c) os romantismos e nacionalismos, ocupando-se com os particularismos populares e com a promoção de um saber das nações sôbre si próprias, através da história, e considerando o direito produto interno de cada uma delas.

Por falar em história, cumpre anotar que a Escola de SavignY não foi intencionalmente antijusnaturalista, e que não rechaçou expressamente a idéia de princípios juridicos extralegais; o que fêz foi substituir a anterior fundamentação da ciência jurídica em preceitos ditos filosóficos, por uma fundamentação no estudo dos costumes e da evolução da "vida" jurídica dos povos. Tanto que num autor como AHrens encontramos uma conciliação - nem tanto lograda - entre jusnaturalismo e perspectiva histórica.

De qualquer modo, a crise do direito natural, ou do jusnaturalismo, era patente. E como ambas as coisas vinham sendo componentes essenciais do enraizamento do pensar jurídico europeu no próprio cerne da vida espiritual do chamado Ocidente, pareceu a certos autores que aquela crise era algo grave, algo alarmante; alguns acharam mesmo que certas formas de negar o direito natural eram deletérias. Assim o famoso Ernst Troeltsch, num exagêro explicável, escreveu um ensaio dizendo que a oposição ao jusnaturalismo ocidental, levada a cabo pelo historicismo alemão, era um perigo para a permanência dos valores culturais europeus e tinha sido inclusive um dos caminhos para o nazismo. Mas deixemos isso.

Para a explanação da teoria do Direito Natural, com todos os seus ingredientes e extensões, entre os séculos XVI e XIX, v. os capítulos clássicos de GIERKE, traduzidos por BARKER num volume intitulado Natural Law and the theory of Society. No número 4 do $\S 16$ (p. 107 ss), investiga as 
relações entre o contratualismo e o jusnaturalismo: êste aparece acolhendo como um "dogma" a hipótese do contrato original. BODENHEIMER encontra três fases na marcha da doutrina do Direito Natural: primeira, a do protestantismo nacionalizado e mercantilista; segunda, a do liberalismo ascendente; terceira, a da voga do conceito democrático de soberania popular (Teoria del Derecho, FCE, México, 1946, cap. VII, p. 129). Mais sôbre isso tudo em Gurvitch, antigo “Natural Law" na Encyclop. of S. Sciences, vol. XI, analisando a seqüência das diferentes versões da idéia, e em M. VHLLeY, Leçons d'Hist. de la Phil. $\overline{d u}$ Droit, Paris, 1957, observando (p. 224) que a dita "laicização" do D. Natural não excluíu das obras dos séculos XVII e XVIII as citações bíblicas. Sôbre a secularização da cultura ócidental moderna, C. Dawson, Progresso e Religião, ed. A. Amado, $1943-\mathrm{O}$ detalhe mencionado no texto, e a que poucos tem dado atenção, está salientado por S. COTTA no ensaio "Les partis et le pouvoir dans les theories politiques du début du XVIIIe siècle" contido na publicação coletiva Le pouvoir, tomo I, PUF, 1956; e sôbre êle publiquei uma nota no n. 3, 1963, de Estudos Universitários, Recife - Sôbre a integração do direito natural leigo na teoria democrática, lembra A. STERN que ela foi promovida pela filosofia da ilustração, abrigadora do racionalismo ( La fil. de la hist. y el problema de los valores, B. Aires, 1963, cap. VI, pág. 166). A alusão a BECKer refere-se ao seu famoso livro (La ciudad de Dios en el s. XVIII, trad., México, 1943). Sôbre a relação do jusnaturalismo de então com a figura dos "direitos" (que eram liberdades), ver J. D. MABBOTT, The state and the citizen, London, 1956, cap. VII; VIILEY, op. cit., p. 277; TAWNEY, Religion and the rise of capitalism, ed. Pelican, 1938, p. 167; C. Brinton, art. "Natural Rights" em Encyclop. of the Sciences, vol. XI, págs. 299 e segs.). Mais sôbre o tema em A. L. MACHado NeTo, Para uma sociologia do direito natural, Salvador, 1957. - O rosário de referências ao vínculo entre jusnaturalismo e revolução, eu o começaria com uma passagem de RECASÉns Siches, "tôda revolución implica uma creencia iusnaturalista, pero especialmente la volucion francesa, magna apoteosis de la fé en el Derecho Natural" (Vida Humana, Sociedad y Derecho, México, 1945, cap. X, p. 322). Seria de perguntar-se, mas sem levar avante agora, se a palavra "creencia" vai aí em sentido orteguiano. Em sentido análogo há expressões em RADDBRUCH, Troeltsch, ALFRED 
Weber, Whitehead, Lacambra, Dilthey, Wolf, etc. todos sentindo $o$ fato de que desmantelar um ordenamento implica elementarmente a concepção de agir em nome de princípios melhores. Como ressalva, cabe porém anotar a ponderação de KeLSEN, para quem as formulações jusnaturalistas, de ARISTÓTELES até hoje, têm um caráter conservador, porque nada mais fazem do que remeter, através de regras que em si nada ordenam de específico, à vigência das normas efetivamente vigorantes em cada época (Justice et Droit Naturel, no vol. coletivo Le Droit Naturel, PUF, v. 959, pp. 23, 27 e 110). Seria aliás o caso de indagar, ainda naquêle caso, se não haveria tantos "tipos" de jusnaturalismo quantos de revolução, históxica e socialmente representáveis; e então o jusnaturalismo, mesmo ligado como um princípio ou um elemento a algo de genérico, ficaria "reduzido" a uma variável. De resto, o próprio conceito de revolução (revolução "autêntica", "definitiva" etc.) vem sendo reivindicado por cada uma das revoluções ocorrentes, mas sem nenhuma conseguir monopolizá-lo. - o ensaio de Troeltsch é As idéias de Direito Natural e de Humanidade na política mundial, e vem como apêndice na edição de Gierke — Barker, citada atrás.

\section{"Direito" natural e "teoria" do direito natural.}

A crítica ao jusnaturalismo, por parte do sociologismo "oitocentista", toma como objeto aquilo que as teorias clássicas do direito natural dizem sôbre o direito. No mesmo sentido, a do historicismo daquêle tempo. Isto é, essas críticas se opõem à idéia de um direito abstratamente considerado, de um direito igual em tôda parte, imutável, invariável, passivel de ser deduzido da mera racionalidade da condição humana, ou da relação desta com a divindade. Opõem-se à universalidade do conceito e ao impalpável do objeto. Argüem que aquela idéia traz a marca de um pensamento estático, de uma "metafísica do lugar natural", de uma concepção incompatível com a positividade de todo verdadeiro direito, ou então com a experiência histórica, com a evolução, com a variação sócio-cultural. Mas situamse sempre perante a "coisa" direito natural, perante aquilo que como tal era apresentado pelas teorias. 
Ora, uma crítica ao nível do século xx não pode contentar-se com isso. Ela tem de referir-se, não só ao caráter histórico do direito, como também ao da teoria do direito. No caso, tem de ser, além de crítica do direito natural, crítica do jusnaturalismo, e "crítica" aqui significa inclusive compreensão e situação. É preciso fazer, portanto, a "redução histórica" das doutrinas mesmas, não apenas do objeto delas. A própria importância dessas doutrinas, em relação com os padrões éticos de pensamento que as impeliram, ressaltará assim.

Essa é portanto uma anotação necessária. As "refutações" do direito natural até aqui têm sido mais ou menos fundadas na idéia da variabilidade do jurídico. E isso tem ensejado sempre as mesmas respostas dos jusnaturalistas: que aquela historicidade implica uma idéia reguladora, que para se reconhecer algo na história como sendo direito exige-se que se disponha de um conceito prévio, etc.. $O$ fato de terem os debates ficado situados nessa faixa, provém do caráter noção do direito de que se dispôs: uma idéia feita em moldes clássicos, substancialista, essencialista, ligada ao tema da justiça e a outros. Com ela, era normal que se alegasse um fundamento "natural" para o direito (e natural ainda que meta-físico). Nêsse sentido, a objeção consistente em dizer que o jurídico, por ser convenção, não pode ser natural, traz o problema, mas não o desdobra. E não o desdobra, nem o resolve, porque de fato a idéia antiga de direito (ou melhor a que atribuímos aos antigos sôbre o que dizemos ter sido o direito dèles) podia ser, e era, natureza. A que talvez não seja natureza é a idéia moderna do direito. Assim, o nuclear numa crítica do direito natural e do jusnaturalismo é a referência à concepção do direito, de que històricamente se trata. A análise do jusnaturalismo deve visar a situação histórica da idéia de direito que baseia o saber jurídico dentro do qual se dá a crença num direito natural. O saber jurídico grego era mais uma reflexão sôbre a justiça; nós é que fazemos dêle um saber jurídico. $O$ romano era jurídico, mas fundava-se, para as definições 
gerais, no dito pelos gregos sôbre fisis e temis. O Ocidente moderno, porém, sob a idéia de positividade com que o legalismo formalizou o caráter estatal das normas, "separou" o natural e o positivo, antes simplesmente distintos (como em S. Tomás) - e separou, correlatamente, a ciência jurídica da filosofia do direito, esta por alguns confundida, em tempos, com a teoria mesma do direito natural. E como o direito que o saber jurídico "sentia" e aplicava era o positivo, o direito natural ficou sendo para o pensamento contemporâneo um. . "problema": não o era para o antigo. É portanto a idéia moderna de direito que não o comporta.

O saber jurídico moderno joga com a noção de um direito cujo conceito se capta independentemente de tempo e espaço, mas se sabe que seus contornos são afetados pela experiência institucional e doutrinária contemporânea. o autoconhecimento dessa experiência, aliás em fase já de transformações e mudanças, é a grande e dramática tarefa das gerações de hoje.

Sôbre a necessidade de ser, a perspectiva histórica, aplicada não só à compreensão do jurídico mas também à da respectiva teoria, ou seja ao "saber" jurídico, pronunciei-me no cap. III, $\S 8$, de meu O Problema da história na ciência jurídica contemporânea (Recife, 1964). A referência ao "essencialismo" contido na idéia de direito herdada dos clássicos, é feito no sentido da crítica de SARTRE: o essencialismo consiste em considerar a realidade cognoscível de algo como independente de suas inserções existenciais, como consistente em um molde intemporal. - A anotação desdobrada nessa parte do texto, pensada como uma observação aos livros sôbre Direito Natural em geral, inspirou-se na leitura do de Leo Strauss, Droit Naturel et Histoire, trad., Plon, 1954. $\mathrm{Na}$ verdade, são puramente sistemáticas certas críticas do Direito Natural, como a de Siches (citada por C. J. GUTIRRRE, em Riv. Internazionale di Fil. del Diritto, nov.-dic. 63, ano XL, fasc. VI, pág. 712), a de Krisen, a de STERNBERG, etc., isto é, omitem o prisma histórico, onde se situa o verdadeiro "sentido" do problema. Há certos pontos, dentro da teoria clássica, que envolvem sérias aporias se mantidos pelo pensamento moderno, e cujo sentido está nas matrizes 
antigas a que se prendem: exemplo, o tema da passagem do "estado natural" ao "civil", constante da literatura seiscentista sôbre Direito Natural. $\mathrm{Na}$ realidade, tal passagem só pode ser tomada como postulado; é como a da pré-história à história, em que, ou o processo de transição já foi histórico, ou não haveria passagem, pois resultantes históricas implicam condições históricas. No caso do natural ao civil, ou o processo seria "social" e então o problema se evapora, ou não, e então há uma impossibilidade empírica. - Acerca do cunho moderno da aura de "problematicidade" vestida pelo Direito Natural, há que acrescentar, com STERN (op. cit., p. 165) que tampouco para a Idade Média era êle algo problemático. $\mathbf{E}$ no caso do pensamento pós-medieval, o "problema" vem da antinomia entre a realidade jurídica contemporânea, em que se estriba a idéia de direito mantida pelo saber jurídico, e o apêgo dos pensadores à idéia de direito atribuída aos clássicos, e conservada como um cânon que se pretende ter continuado válido por via intelectual, independentemente das mudanças da experiência jurídica. - Recolhendo a idéia de serem jusnaturalistas as revoluções, uma parte correta dela estaria em que elas (as grandes) podem de cada vez refazer a concepção do direito mesmo, com o que se faz sempre possível retomar idéias do tipo antigo e pretendidamente permanente, inclusive a idéia da justiça, que entra na temática do direito pelo nível dos “princípios” que é onde vigora o problema do Direito Natural. Valha lembrar, contudo, que mesmo aí latejam diferenças: a justiça, à helênica e à clássica, era pensada em têrmos de harmonia, e agora o é em têrmos de reivindicações sociais e de técnicas respectivas.

\section{Reflexões pouco conclusivas.}

Voltando ao assunto liberdade: vejamos a situação em que ela ficou durante o século XIX, sob os diversos puxavantes ideológicos. Por um lado, perigosos apogeus, desde o princípio kantiano de que a existência da moralidade supõe a de uma vontade livre. Socialmente caracterizada, a tendência continuadora das revoluções individualistas, considerando liberdade a potencialidade de conduta lícita existente em cada homem, limitada pela ordem geral, sim, 
mas em última instância fundamentadora desta. Igual mente caracterizada, a inclinação conservadora, acentuando os valores tradicionais, e dando como liberdade a aceitação das continuidades orgânicas da nação, em cujo seio cada homem vive. Nos socialismos de timbre utópico, uma conseqüência do próprio liberalismo e do jusnaturalismo, como defesa extremada dos interêsses "de cada um"; no marxista, uma oposição ao jusnaturalismo, por burguês e ideológico.

No século $\mathrm{xx}$, um painel de combinações e revisões dos temas do anterior. A própria diferença entre liberdade antiga e moderna, acentuada pelos autores do xIx, vai sendo revista e reduzida A idéia de liberdade, acusada por tantos de ilusão idealista, sai adotada como um pressuposto, tanto pelo raciovitalista ORTEGA, como pelo materialista SARTRE. Revisões também do conceito de democracia e das marcas individualistas que trazia. A discussão sôbre a liberdade, dantes ligada ao tema do livre arbitrio e do determinismo, instala-se no campo social e se amarra a conceitos sociais e econômicos, alienação, planejamento, justiça social etc.. Onde se tem oportunidade de reclamar reformas, denuncia-se a liberdade como vã e ôca; onde o poder absorve as reclamações, reclama-se a liberdade. Se se quer acusar um regime por não praticar a igualdade, fala-se da liberdade inútil; se se quer acusar o igualitarismo como falso ou insuficiente, é a liberdade o que se diz estar faltando.

Enquanto isso a teoria do direito natural, posta na crise já mencionada, contra a qual já lutara durante a ascensão do neotomismo ao tempo de Taparelli, retoma no século xix uma série de veredas pelas quais tenta refazer-se. Com STAMMLER, proculou-se uma composição um tanto artificiosa, com o conceito de um direito-natural-de-conteúdo-variável; com GÉNY e com a escola do "direito livre", a idéia de uma superação do direito puramente legal ensejou a valorização das tendências jusnaturalistas; e até hoje prossegue o movimento, com filósofos e juristas os mais eminentes a dar-lhe impulso, e estão no caso Der. Vecchio, Welzel, Leo 
Strauss etc.. Fala-se, então, de um "renascimento" ou de um "eterno retôrno" (Henri RoHmen) do Direito Natural, um retôrno meio palingenésico e algo quiliástico. $\mathrm{O}$ fundamento do entusiasmo de seus defensores é que, não só a superação das filosofias empiristas e o advento da axiologia requerem que se retome o tema de um direito suprapositivo, como também a sangueira das guerras e a torpeza dos regimes violentos pedem que se considere como jurídico algo que paire acima do nível dos comandos estatais. 0 direito natural renascente seria então um novo bastão de TAUNHäUSER, a reflorir na redenção.

Vejamos, porém. Há uma série de argumentos contra a idéia de direito natural que se mantêm, e aliás para o repúdio às mazelas do século o apêlo a uma moral humanística seria bastante. Independente disso, entretanto, é preciso perguntar se se pode reeditar sem mais aquela uma concepção cujo molde cultural se vinculou històricamente a uma série de experiências culturais, hoje postas de lado ou transformadas. Considero os reclamos jusnaturalistas de hoje, úteis como advertência contra o positivismo jurídico, não porém bastantes para a restauração de um modo de pensar. E hoje o acúmulo de consciência histórica, como consciência crítica, faz compreender que a situação de uma idéia como a do direito natural é precisamente essa: uma situação. de idéia. Uma teoria jurídica històricamente crítica deverá considerar, não mais ou não puramente o tema "do" direito dito natural, mas sim — ou principalmente - o papel do jusnaturalismo como doutrina, e portanto como fator de conduta. Nisso, a multissecularidade da idéia do direito natural, que poderia apresentar-se com pretensões de provas da "existência" de seu objetc, pode ser tomada em sua perspectiva autêntica: a da longevidade de uma idéia que de vez em quando tem atuado nas consciências humanas, e que representa a intuição permanente de uma exigência ética para o direito.

E por outro lado, parece que o que se chama de Ocidente tem uma tendência aos dualismos. Nesse caso, a con- 
traposição de um direito ideal ao vigente seria um seu corolário; mas isso não é bem direito natural, e o jusnaturalismo não se reduz a essa contraposição. Não escondo minha simpatia pela possibilidade de distinçôes entre ideais e vigências, mesmo porque as utopias são o sal dos projetos humanos: mas resisto a admitir um direito natural como tal. E se reconheço o jusnaturalismo como fôrça histórica, é precisamente com esta ressalva: fôrça capaz de acompanhar-se de uma lucidez que, ao menos depois da obra dessa fôrça, veja que ela é histórica, que muda, e que seus supostos e seus produtos são sempre mutáveis.

A revisão das idéias do século XIX sôbre suas diferenças perante a "liberdade" grega foi esboçada por CRoce no cap. V de seus Elementos de Política. Sôbre a reposição, contida no marxismo, do tema da liberdade humana e de seu regime social, ver HANS BARTH, Verdad y Ideologia, México, 1951, p. 101. Sôbre os debates jusnaturalistas em nosso século, v. o livro notável de H. Welzel, Derecho Natural y Justicia Material (trad. Aguillar, 1957).

- Seria de pensar-se, ante tudo isso, que a curva do aumento da liberdade, que subiu durante os séculos mais recentes, vai descendo. O fato, porém, é que êsses séculos deram ao homem ocidental o hábito da lucidez, ou ao menos - desejo dela como exigência ou critério. Como ser lúcido, porém, se a luta dos absolutismos políticos, militares, técnicos, econômicos, publicitários, ou o que seja, reimplantar moldes dogmáticos sôbre o espírito humano a pretexto de inseguranças sociais? Terá o liberalismo sido, além de breve, inútil?

$$
(5,7 \text { e } 11 \text { - set. } 65)
$$

